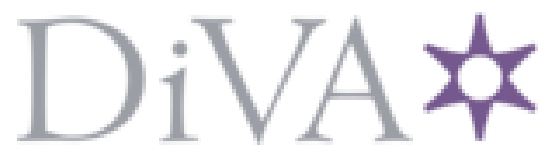

http://www.diva-portal.org

This is the published version of a paper published in Project Management Journal.

Citation for the original published paper (version of record):

Biedenbach, T., Jacobsson, M. (2016)

The Open Secret of Values: The Roles of Values and Axiology in Project Research.

Project Management Journal, 47(3): 139-155

Access to the published version may require subscription.

N.B. When citing this work, cite the original published paper.

Permanent link to this version:

http://urn.kb.se/resolve?urn=urn:nbn:se:umu:diva-119324 


\section{The Open Secret of Values: The Roles of Values and Axiology in Project Research}

Thomas Biedenbach, Umeå School of Business and Economics, Umeå University, Umeå, Sweden Mattias Jacobsson, Umeå School of Business and Economics, Umeå University, Umeå, Sweden

\section{ABSTRACT}

The purpose of this article is to explore the roles and potential benefits of axiology and value theory in project research. This is done through (1) an exploration of the essentials of axiology and value theory; (2) a review focused on how values have been used in project research; and (3) a reflection based on the historical-logical development ofand paradigmatic influences on-projects and their management. It is concluded that project research would benefit from a more encompassing philosophical treatment of axiology beyond merely acknowledging values as a thematic concept or as part of a project management methodology.

KEYWORDS: epistemology; ontology; value theory; axiology; paradigm

\section{INTRODUCTION}

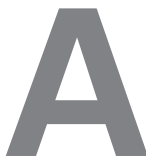

central question throughout human history has been: What is actually desirable and/or good? The hedonist response would probably be 'pleasure'; the pragmatist would be 'solving the problem'; and the followers of Immanuel Kant, something along the line of 'a good will.' But what is, or has been, perceived as desirable and 'good' in project research? And is it fruitful, or even possible, to consider such question(s) beyond the mere quality of the production of research itself? Also, would there be benefits from more encompassing treatment and understanding of values and value theory in project research? In this article we will explore these and other related issues in our quest to take stock of the roles of values and axiology in the field of project research.

Considering the research on projects as one broad field, it is clear that development over the last decades has brought about ever-increasing methodological, epistemological, and ontological variations (Smyth \& Morris, 2007; Biedenbach \& Müller, 2011; Bredillet, 2010), as well as extensive diversity in both the rationale and types of empirical phenomena under study (Morris, 2010; Jacobsson \& Söderholm, 2011; Söderlund, 2011). It is also well known that the existing knowledge base has been co-developed through concurrent insights from academics, consultants, practitioners, and strong professional associations (Turner, Pinter, \& Bredillet, 2011). These influences, taken together, have created a pluralistic and strong field where various scientific approaches are both infused into the bulk of knowledge and represented in a variety of publications, which arguably illustrates the vibrancy and increasing maturity of the field (Söderlund, 2011). Despite this, in many ways striking progression, axiology, value theory, and the role values play in research, are rarely explicitly addressed, even if scholars have recognized the roles philosophy of science, in general, play in project research (see, e.g., Mingers, 2003; Gauthier \& Ika, 2012). A more general and indirect recognition of values has nevertheless been visible through recent contributions in the Special Issue on Ethics in Project Management (International Journal of Managing Projects in Business, Vol. 7, Issue 4), and through research on sustainability and projects (see, e.g., Abidin \& Pasquire, 2007; Edum-Fotwe \& Price, 2009). Still, based on the lack of explicit focus on value-related issues, ${ }^{1}$ following the contemporary societal development in which both policymakers and organizations alike are increasingly concerned with values for educating an ethical and sustainable responsible workforce, here we attempt to take stock of the current treatment of values and axiology in the field of project research. Ultimately, the purpose

${ }^{1}$ For some notable exceptions see Helgadóttir, 2008; Corvellec \& Macheridis, 2010; Bredillet, Tywoniak, Dwivedula, 2015.
Project Management Journal, Vol. 47, No. 3, 139-155 (C) 2016 by the Project Management Institute

Published online at www.pmi.org/PMJ 
is to explore the role and potential benefits of axiology and value theory in project research. We hereby hope to spur a well-needed discussion with regard to the future of project management and the role of the philosophy of sciences within the project research field.

In our article we combine a review with a conceptual approach to achieve this quest in three interrelated steps. As a starting point we will outline some essentials of the philosophy of science, axiology, and value theory as it has been conceptualized by both researchers in other fields and by philosophers with an interest in value theory per se. Thereafter, we will undertake a review of the project research field, with a focus on how values have been used in a broad sense. As a third step, complementing the review, we will provide a short historical-logical overview, outlining the premodern-, modern-, postmodern-, and hypermodern project management perspectives (Gauthier \& Ika, 2012), and juxtapose these with various value approaches. Through these three steps, we provide a multidimensional snapshot of the current state of the field with regard to how values are (and have been) used and not used. Taken together, we not only report on the state of the field but also show how valuesdespite what is sometimes claimed-are already implicitly present as a part of, for example, the underlying philosophical assumptions and discuss the consequences thereof. We conclude that being more explicit about values and what is valued by researchers, is important for the development of the field, because it is based on and takes pride in, the diverse sources of contribution, all implicitly instilled in various value types. A central argument of philosophical relevance here is the closeness to practitioners and the often-present consequentialist rationale, where claims of 'good' or 'bad' in research outcomes implicitly have a bearing on what ought to be (or not be) done in practice. Without the proper understanding and reflection (from the researchers' points of view) of values and why something is valued positively or not, the practical implications given could just as well encourage malpractice as desired practice. We end with a reflection and a few suggestions for how future studies might be able to incorporate axiology in general and value theory, specifically, for the generation of promising new research endeavors and debates encompassing philosophy in project research.

\section{The Philosophy of Science}

The philosophy of science, or research philosophy, refers to the belief system and basic assumptions that serve as the underpinning in the creation of knowledge (Saunders, Lewis, \& Thornhill, 2016). In essence, it involves all steps and considerations that researchers make when developing new insights within a particular field of research. Philosophy of science thus comprises conscious and unconscious assumptions and considerations, regarding the nature of reality (ontology), the creation of knowledge and understanding (epistemology), as well as the role of values and their influences on the knowledge creation process (axiology). In practice, such philosophical attention is of central importance to both the research process and implications of all scientific inquiry, since the quality of research comes from the reflective relationship between the researchers' philosophical positioning and how the research is undertaken (Alvesson \& Sköldberg, 2009). Central to philosophy of science-even if often disregardedwe thus have the core concepts of this article; in other words, axiology and value theory.

\section{Axiology and Value Theory}

The word 'axiology' originates from two Greek roots, axios and logosaxios bearing the meaning of 'worth' or 'value' and logos the meaning of 'logic' or 'theory.' Combined, we have the notion of 'a theory of value.' The use of the term first appeared in research in the beginning of the twentieth century
(Hart, 1971), but as exemplified in the initial vignette of this article, the underlying questions addressed are as old as mankind. Or, as eloquently put by Hart (1971, p. 29): "the notions of good and bad, right and wrong, beautiful and ugly are as old as the real and apparent." The emergence of the term 'axiology' thus represents an attempt to bring together, and critically examine, a wide variety of already existing and overlapping questions related to the essence of goodness, right conduct, value, and obligation (Hiles, 2008). In other words, axiology addresses questions related to what is valued and considered to be desirable or 'good' for humans and society. In this article, some of these ideas and concepts are applied to the project research domain.

There are of course many ways to approach and understand values, but given the limitations of this research article we can explore only a few of them (for the interested reader, see, for example, Allchin, 1998 or Edwards, 2014, for more extensive discussions on various approaches). One often used classification is outlined by Rescher (1969), who divides values into eight basic types: material and physical value; economic value; moral value; social value; political value; aesthetic value; religious value; and intellectual value. Even if this categorization provides a good empirical overview of what is in various ways valued in society, it does not help us to determine what (for example) different values have in common. A way to do this, however, would be to distinguish between what is intrinsic and instrumental good-'intrinsic' meaning good due to the nature, the latter referring to effective means to attain the intrinsic goods (Pojman \& Fieser, 2011). Similar distinctions between intrinsic and instrumental values have been around since the time of Aristotle and Plato. Often used and building on this classical categorization of 'good,' Hartman (1961, 1962, 1967; Mueller, 1969) argued for three axiological dimensions: intrinsic, extrinsic, and systemic values. Each of 
these dimensions represents not only a different type of value, but also different ways to value something. In our assessment of the world (where for us, science is a central part), Hartman (1967) argues that humans value everything in accordance to one, or a combination, of these three dimensions; consequently, they overlap with the empirically closer categories used by Rescher (1969). Before delving into how values have been used in project research, and discussing the consequences thereof, a further exploration of the three different value types is in order, starting with intrinsic value.

\section{Intrinsic Value}

Intrinsic value is to be defined as the actual or pure value of something. It is often described as the value an object (someone or something) has "in itself" or "in its own right" - whether it be an experience, a person, an act, or nature. Intrinsic value is consequently not derived from, or related to, the fulfillment of certain criteria or concepts, but rather it is universal; therefore, it is closely related to moral/value absolutism (as opposed to moral or value relativism), in the sense that value is inherent in the 'something' and not only a result of cultures or perspectives (Hartman, 2014). In the case of humans, intrinsic value consequently arises from the essence and integral totality of all personal attributes, namely the value of the character or personality. The goodness of a person, in terms of intrinsic value, is thus not based on a membership to a certain class of group.

Exemplifying with research on for example environmental sustainability, it is often stressed that nature has an intrinsic value. That is, value beyond being an economic resource, a basis for economic growth, or even potentially providing an opportunity for ecotourism (O'Neill, 1992; Zimmerman, 2001). Nature consequently has a value "in itself," compared to, for example, money. Most people would still agree that money is valuable, but only few would say that money is intrinsically good; rather, money is supposed to be good because it may lead to other good things. Going back to the 'hedonist' example in the introduction of this article, a hedonist would consider 'pleasure' as something of intrinsic value, but having a lot of money may still be important for the hedonist, as it can be used as a means to generate pleasure and happiness.

\section{Extrinsic Value}

The easiest way to describe "extrinsic value" is that it is value that is not intrinsic. It is consequently not the value an object (someone or something) has "in itself," "for its own sake," or "in its own right," but rather for the sake of something else to which it is related to-as for example money and pleasure. Anything of extrinsic value is therefore, according to Hartman, (2014, p. 14) “. . . not supposed to be good in itself but in its function".

Hartman (2014) further describes extrinsic values in terms of 'extensional goodness' (i.e., that goodness arises from an extension of a certain concept), referring to something outside such as the relation between 'the thing' and the class/category. Something being of extrinsic value thus requires that it belongs to a certain class or category (Hartman, 2014). In this respect, the extrinsic value of something is connected to the functionality it has in a specific context, or expectations related to the association of belonging to a certain class or category. This is not to say that something with an extrinsic value cannot have an intrinsic value. Returning to the example of humans: their extrinsic value-or lack of valuewould be due to their function as, for example, a teacher, project manager, or politician and their contributions to something (or someone) else. Here, often-discussed issues with the notion of extrinsic value are the questions: (1) What sort of relation must exist between the intrinsic and extrinsic? And (2) How close does this relation between the two need to be?
Following up on these issues, one could say that intrinsic value comes first, before extrinsic value, because in order for extrinsic value to make sense, intrinsic value needs to be taken into consideration (Hartman, 2014). This does not mean that one value type determines the other, because being, for example, a (good) person, and being a 'valued function in a system' are different things. Something can therefore be extrinsically valuable, but not intrinsically or vice versa. In terms of projects, someone can consequently be a good person but a bad project manager, or a 'bad' person but still a good project manager.

\section{Systemic Value}

Beyond intrinsic and extrinsic values, there is also a logical or systemic value (Hartman, 2014). According to Hartman (1961, p. 391), a systemic value is "the formal pattern of systemic valuation"; meaning that, for something to have such a value it has to follow (or fulfill) the logical structure set up for that specific 'something.' There is consequently no room for degrees of value, but rather it affirms to a digital understandingeither belonging (i.e., being valued), or not belonging (i.e., not being valued). Because the systemic valued 'something' is purely made up by its own characteristics, the 'something' cannot fail to have a systemic value as long as it is what it is (Edwards, 2014).

Hartman (1961) argues that all valuation of this kind reduces the valued 'something' to an element in a system and exemplifies it with a marriage in a specific legal system-either two individuals are legally married, or they are not. There is no in-between, and it all depends on the fulfillment of the specific criteria within that specific logical structure. Being legally married in 'a specific system,' however, should not be confused with any type of marriage (or relationship), because each empirical phenomenon has overlapping systems. Hartman (1961, p. 392) states: “. . . any ordinary empirical thing, event 
or situation has its systemic counterpart with which it must not be confused." The 'systemic value' is consequently closer related to moral- or value relativism, because the assessment is based on an outside and manmade system, which is culturally dependent. What is valued, or not valued, consequently changes depending on the specific system.

\section{Research Approach}

Having presented some basics of value theory and outlined the three axiological dimensions of value (Hartman 1961, 1962, 1967, 2014), as the next step, we will assess the use of value(s), and value-related concepts, in the field of project research. Similar to Turner et al., (2011) and Cameron, Sankaran, \& Scales, (2015) we have reviewed the three main journals that have an explicit focus on project research, as well as two more recent (project-oriented) journals to gain a comprehensive overview of the contemporary field. Even if the review is structured and methodical in its approach, it should be acknowledged that it is not conducted as 'a systematic review' in the strict sense ( $c f$. Tranfield, Denyer, \& Smart, 2003). The journals included in the review (in alphabetical order) are:

- IEEE Transactions on Engineering Management (IEEE-TEM),

- International Journal of Managing Projects in Business (IJMPB),

- International Journal of Project Management (IJPM),

- International Journal of Project Organisation and Management (IJPOM), and

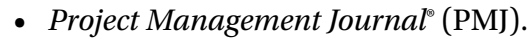

With the review not being systematic in the strict sense, we have thus thoroughly described the review process and the steps undertaken. The review and analysis are based on all publications from each journal, which were available online as digital copy, up until May 2015: IEEE-TEM = 52 years, $I J M P B=7$ years, $I J P M=32$ years, $I J P O M$ $=7$ years, and $P M J=18$ years, for a total of 116 volumes. In order to establish a comprehensive overview of how value(s), directly or indirectly, has(have) been used in published papers, a total of 33 search terms have been iteratively generated based on: (1) an assessment of existing conceptualizations of axiology and value theory (see e.g., Hartman, 1967; Hart, 1971; Mingers, 2003; Olson, 2005); (2) by reading value related research in the field (see e.g., Helgadóttir, 2008; Corvellec \& Macheridis, 2010; Bredillet et al., 2015); and (3) by including additional search terms that emerge from search hits as suitable concepts. The complete list of search terms used in our review is presented in alphabetical order in Table 1.

Furthermore, in line with Cameron et al. (2015), the review was conducted primarily using the publisher's search engines for each specific journal, which are: IEEE Xplore for IEEE-TEM articles since its first issue under the new name in 1963 (Vol. 10, Issue 1) until 2015 (Vol. 62, Issue 2); Science Direct for IJPM articles from 1983 (Vol. 1, Issue 1) until 2015 (Vol. 33, Issue 5); EBSCO using Business Source Premier for PMJ articles from 1997 (Vol. 28, Issue 2) until 2015 (Vol. 46, Issue 2); Emerald Insight for $I J M P B$ articles since its foundation in 2008 (Vol. 1, Issue 1) until 2015 (Vol. 8, Issue 3); and Inderscience Search for IJPOM articles since its foundation in
2008 (Vol. 1, Issue 1) until 2015 (Vol. 7, Issue 2). The decision of which search engines to use for the review was determined by the following criteria: first, to maximize the searchable range of publications throughout the years, and second, the search functionality. It was unfortunately not possible to use the same search engine (such as EBSCO) across all journals without strongly limiting the years of publications (e.g., from 1994 onward instead of 1963 for IEEE-TEM). However, EBSCO was the preferred search engine for $P M J$ (compared with the publisher's own search engine), because of the limited access through our university library (Wiley Online has only been accessible since 2007). Overall, the search functionalities are still comparable; thus, a wider range of publication years was judged as more important for the purpose of conducting a simple but extensive content search within article titles, keywords, and abstracts over the years. With the focus on the key sections of the articles, we ensure getting hits only where the value-related search terms are a dominating theme. In contrast, with a full text search we would also get hits when the term is only occasionally used, which would require specific consideration.

Looking at the search terms presented in Table 1 more closely, there

\begin{tabular}{|c|c|c|}
\hline \multicolumn{3}{|l|}{ Search Terms } \\
\hline Axiological & Evaluating & Net present value \\
\hline Axiology & [...] Evaluation & PERT \\
\hline Earned quality method & Extrinsic motivation & [environmental] sustainability \\
\hline Earned value analysis & Extrinsic reward & [environmentally] sustainable [...] \\
\hline Earned value management & Extrinsic value & Systemic value \\
\hline Earned value methodology & Instrumental value & {$[\ldots]$ Value $[\ldots]$} \\
\hline Ethic & Intrinsic motivation & Value analysis \\
\hline [...] Ethics & Intrinsic reward & Value creation \\
\hline Ethical $[\ldots]$ & Intrinsic value & Value outcome \\
\hline Ethical value & Moral [...] & Value theory \\
\hline Evaluate & Morality & Valuing \\
\hline
\end{tabular}

Table 1: Review search terms. 
are three issues that should be noted. First, as indicated by "[ . . . ]," some of the search terms can come in many different combinations and specifications. Rather than searching for all different varieties, we focus on the search terms of the compound noun that relates to the value terminology (i.e., instead of, for example, searching for "business ethics" and "industry ethics," we search for "ethics"). Second, there is a certain overlap between the basic forms of some words, for example "value," which is included in many specific search terms, such as "value analysis." In Table 2, however, we present the hits for the particular search term, despite the mentioned irregularities. Later on, we will aggregate these into a number of different categories, where value will be an overarching aggregate across the different categories. Third, some search words may have various meanings depending on the context, for example: "sustainability" where environmental sustainability relates to values, whereas a sustained or sustainable performance does not. Therefore, only articles that address environmental sustainability were counted for the frequencies.

When running the different queries we have consistently used the same procedure for specifying the resulting frequencies. In the initial step, we selected the particular journal and a certain time period; then we entered a search term and searched for hits, first within the article's title, then within its keywords; and last, within its abstract. In the second step we evaluated the resulting number of hits for their appropriateness and excluded, for example, book reviews, corrections to published articles, calls for papers, and editorials, which were not counted for the frequencies. Articles in press were also not included because they are not indexed in the same way as the other articles, and our aim was to limit our review to publications up to May 2015. When an article indicated additional relevant search terms that were not among our initial search terms, in an additional step, we added those terms in order to gain a more comprehensive overview of the project field. In a final and concluding step, we inductively categorized the results into five distinct value categories: where value is used within the research process, as a thematic concept, according to value theory, as an outcome, or as project management methodology. The five categories consequently represent different ways in which values are used within published research.

The aggregated categories have enabled us to explain how values are treated in published research over the years on a distinct but aggregated level. For mapping the treatment of values over time, we have broken down the years between 1963 and 2015 into three periods. The distinction of the time periods is based on the emergence of research streams that have had a major impact on the project field with new perspectives. First, in 1995, the conceptualization of projects as temporary organizations (Lundin \& Söderholm, 1995; Packendorff, 1995; Hällgren et al., 2012); and, second, the initiative of critical project management studies and rethinking effort in 2006 (Cicmil, Williams, Thomas, \& Hodgson, 2006; Hodgson \& Cicmil 2006), which both have had distinctive influences on the field (Jacobsson, Lundin, \& Söderholm, $2015,2016)$. Therefore, those years have been used for establishing the three different time periods with the emergence of new value-related perspectives.

\section{A Review of the Assessment of Value in Project Studies}

An overview of the total frequencies on the different search terms across the different journals is presented in Table 2 . Value is highlighted as a separate row, and can be seen as a key aggregate due to its overlap with search terms across several value categories. This table only visualizes the search terms that have received hits in the article title/keywords/abstract query; hence, from the 33 search terms in Table 1 only 29 search terms remain in Table 2 .
The search terms that did not provide any hits were axiology, value theory, extrinsic value, and systemic value. Note, that the table just shows the frequencies of the queries within the article section separately. Thus, $1 / 1 / 1$ on a search term could mean that it was one article that included the term in the title, keywords, as well as in the abstract, but it could also be-although less likely-that the term was used in two or even three articles, each contributing to either the title, keyword, or abstract count.

Furthermore, the search terms are inductively grouped together in the five value categories; after each set of search terms, we present the totals per journal for each value category. The content and implications of these categories will be discussed later. For better readability, $0 / 0 / 0$ is replaced by a dash $(-)$ in the table. In two of the journals some queries are impossible to specify and thus marked $N A$. In IJMPB, the articles include a structured abstract that contains a section on originality/ value; therefore, each article receives a hit in the "value" query, and the efforts in gaining a specific number by going through each abstract manually are not within a reasonable scope for a simple but comprehensive review. In IJPOM, the Inderscience Search features do not allow any queries within article abstracts; however, a full text search has been conducted in order to conclude from the abstracts when possible. Papers that have received too many hits in the full text search (i.e., value [128 hits], evaluating [44 hits], and evaluation [99 hits]) are designated with $N A$ for the same practical reasons as those in the $I J M P B$.

Throughout the reviews of all five journals, we found only one article that explicitly addresses the terms axiological, intrinsic value, ethical value, value outcome, earned quality method, and earned value methodology. Whereas other search terms are present, although with varying emphases, across all journals, including ethics, evaluating, evaluation, earned value management, PERT, 
The Open Secret of Values: The Roles of Values and Axiology in Project Research

\begin{tabular}{|c|c|c|c|c|c|}
\hline $\begin{array}{l}\text { Search Terms and Hits } \\
\text { (Title/Keywords/Abstract) }\end{array}$ & $\begin{array}{l}\text { IEEE-TEM } \\
1963-2015\end{array}$ & $\begin{array}{l}\text { IJPM } \\
\text { 1983-2015 }\end{array}$ & $\begin{array}{l}\text { PMJ } \\
\text { 1997-2015 }\end{array}$ & $\begin{array}{l}\text { IJMPB } \\
\text { 2008-2015 }\end{array}$ & $\begin{array}{l}\text { IJPOM } \\
\text { 2008-2015 }\end{array}$ \\
\hline Axiological & - & - & - & $0 / 0 / 1$ & - \\
\hline Total research process & - & - & - & $0 / 0 / 1$ & - \\
\hline$[\ldots]$ Value $[\ldots]$ & $35 / 13 / 162$ & $50 / 71 / 221$ & $25 / 24 / 59$ & 4/6/NA & 3/4/NA \\
\hline Ethic & $0 / 0 / 1$ & $0 / 1 / 3$ & - & - & - \\
\hline [...] ethics & $0 / 1 / 1$ & $2 / 7 / 10$ & $4 / 4 / 5$ & $1 / 4 / 3$ & $0 / 1 / 1$ \\
\hline Ethical $[\ldots]$ & $2 / 1 / 3$ & $6 / 4 / 8$ & $0 / 1 / 6$ & $3 / 1 / 4$ & - \\
\hline Evaluate & $1 / 0 / 65$ & $1 / 1 / 108$ & 0/0/15 & $1 / 0 / 14$ & - \\
\hline Evaluating & $17 / 0 / 58$ & $16 / 0 / 47$ & $3 / 0 / 5$ & $2 / 0 / 3$ & 2/0/NA \\
\hline [...] evaluation & $54 / 12 / 142$ & $51 / 59 / 139$ & $9 / 8 / 18$ & $4 / 12 / 16$ & $3 / 9 / N A$ \\
\hline Extrinsic motivation & - & $0 / 1 / 1$ & $0 / 1 / 1$ & - & $0 / 0 / 1$ \\
\hline Extrinsic reward & $0 / 0 / 1$ & - & $1 / 0 / 1$ & - & - \\
\hline Intrinsic motivation & $0 / 0 / 1$ & - & $0 / 1 / 1$ & 0/0/1 & - \\
\hline Intrinsic reward & $0 / 0 / 2$ & - & $1 / 0 / 1$ & & - \\
\hline Moral $[\ldots]$ & $0 / 1 / 1$ & $1 / 0 / 3$ & - & $0 / 1 / 5$ & - \\
\hline Morality & $1 / 1 / 1$ & $0 / 0 / 1$ & - & - & - \\
\hline [environmental] sustainability & $4 / 6 / 4$ & $2 / 5 / 3$ & $1 / 2 / 1$ & $2 / 0 / 0$ & - \\
\hline [environmentally] sustainable [...] & $4 / 2 / 7$ & $2 / 3 / 6$ & $1 / 0 / 2$ & $3 / 3 / 5$ & - \\
\hline Valuing & $1 / 0 / 1$ & $0 / 0 / 1$ & $0 / 0 / 1$ & - & - \\
\hline Total thematic concept & $84 / 24 / 288$ & $81 / 81 / 330$ & $20 / 17 / 57$ & $16 / 21 / 51$ & $5 / 10 / 2$ \\
\hline Ethical value & $1 / 1 / 1$ & - & - & - & - \\
\hline Instrumental value & $0 / 0 / 1$ & - & $0 / 0 / 1$ & - & - \\
\hline Intrinsic value & $0 / 0 / 1$ & - & - & - & - \\
\hline Total value theory & $1 / 1 / 3$ & - & $0 / 0 / 1$ & - & - \\
\hline Value analysis & $2 / 0 / 0$ & $0 / 2 / 2$ & - & $0 / 1 / 0$ & $0 / 0 / 1$ \\
\hline Value creation & $0 / 0 / 4$ & $4 / 3 / 11$ & $1 / 0 / 1$ & $0 / 1 / 1$ & - \\
\hline Value outcome & - & - & - & $0 / 0 / 1$ & - \\
\hline Total value outcome & $2 / 0 / 4$ & $4 / 5 / 13$ & $1 / 0 / 1$ & $0 / 2 / 2$ & $0 / 0 / 1$ \\
\hline Earned quality method & $1 / 0 / 1$ & - & - & - & - \\
\hline Earned value analysis & - & $0 / 1 / 3$ & - & - & $0 / 1 / 1$ \\
\hline Earned value management & $0 / 1 / 3$ & $3 / 8 / 12$ & $3 / 2 / 4$ & $1 / 0 / 2$ & $2 / 2 / 1$ \\
\hline Earned value methodology & - & $0 / 0 / 1$ & - & - & - \\
\hline Net present value & $1 / 0 / 4$ & $1 / 2 / 9$ & $1 / 2 / 2$ & - & $0 / 0 / 1$ \\
\hline PERT & $11 / 2 / 19$ & $8 / 15 / 27$ & $2 / 3 / 3$ & $1 / 0 / 1$ & $2 / 3 / 3$ \\
\hline $\begin{array}{l}\text { Total project management } \\
\text { methodology }\end{array}$ & $13 / 3 / 27$ & $12 / 26 / 52$ & $6 / 7 / 9$ & $2 / 0 / 3$ & $4 / 6 / 6$ \\
\hline
\end{tabular}


and of course, value representing the aggregated key concept.

Apart from the general observation that 'value and value-related terms' are only rarely used a number of initial 'general' observations can be made from this part of the review. First, it can easily be concluded that some of the journals seem to be more open to value topics (here IJPM stands out), whereas other journals do not seem to have values as a regular topic of inquiry (for example, $I J P O M)$. Within IJPM's journal aims and scope, the description of three exemplified covered topics-namely, project evaluation, quality assurance, and motivation and incentives-may contribute to the large number of value-related articles. In contrast, IJPOM's journal scope does not provide any particular explanation for the low numbers of value-related articles despite presenting a vast number of covered topics. Reflecting a bit further on the journals presented in Table 2, it also becomes evident that IEEE-TEM has the broadest coverage of value-related terms and categories of all the reviewed journals. $P M J$ seems to address value mostly as a value aggregate, whereas $I J M P B$ is a promising young journal that already contributes to various value categories, except for the value theory category. Furthermore, IJPOM is a new journal, which thus far has emphasized contributing to the thematic concept and project management methodology categories. Another general observation that can be made is that the basis value theory/axiological categories (previously presented in this article) are rarely used. In addition, axiology/axiological as a concept is almost never used (see the exception of one article using axiological in IJMPB). One plausible explanation is that this terminology is also fairly new in general management even if the notion and discussion of the consequences thereof are prospering.

To move beyond these initial and 'general' observations we have inductively, based on the way that value and valueassociated concepts are used, clustered the search terms into five categories (see Table 3). These categories are: (1) articles in which value terms appear as a part of the research process; (2) articles in which value (and value-related concepts) are used in a thematic way; (3) articles that have used value theory as a basis or as a part of the analysis; (4) articles in which value is treated as an outcome; and (5) articles in which value is part of the project management methodology.

These categories are developed mainly for two reasons. First, through the categories we are able to schematically track the advance of various valuerelated aspects over time, and second, we are able to discuss the results of the review on a more aggregated level, rather than solely focusing on each term. Even if a discussion/review of each search term might have been possible (given that it would have been the entire focus of this article), we believe that the understanding would have become very scattered and not have provided a better understanding of the role of values per se. We also want to stress that the categories should not be interpreted as 'schools' or 'structured streams of research' with similar goals, but rather as areas in which project studies seem to have-or potentially have-an overlapping interest, or utilize similar inquiries related to values (i.e., the categories represent common ways that value and value-related concepts have been used).

Before we discuss the content and describe the evolution of each category, a few restrictive circumstances need to be highlighted. Concerning the review, it is important to note that IJPM has increased its issue numbers over the years included in the review-from four issues (until 1994) to six issues (1995-2000) and eight issues after 2001 through 2015. The frequencies, therefore, must be put in relation to the total number of papers published during each time period. Also, the number of available or reviewed journals per time period and year range differ; in the first period of 31 years, two journals were included; in the second period of 11 years it was three journals; and the third period comprised of approximately 9.5 years, with all five journals included. Despite this, and compared with the first time period before 1995, ethics and values became a regular debate. In terms of project management methodology, both PERT and earned value management, have a long history, but play a lesser role than the thematic concepts relating to value, ethics, and sustainability. Within each value category we have identified the dominating search term that has received the most hits across all journals, commented on terms that are rarely used, and reflected on the sum of each category across the different journals.

\section{Value in the Research Process}

The first category consists, as mentioned, of the papers in which value terms appear as parts of the research process. In this category we searched for axiology-related terms that describe the role values play in the research process. When looking at the frequencies it becomes obvious that, overall, researchers are silent about axiology. The 'research process' category is only represented by one single article in $I J M P B$, in which the concept axiological has been used. However, within our review we can only spot papers that explicitly refer to axiology as a philosophical term, whereas implicitly reflections and statements are impossible to spot with the design we have chosen for the review. The very limited presence might thus also, to some extent, be explained by the fact that the research approach described in abstracts avoids description of the philosophical underpinnings and that findings are summarized without their philosophical frame. By that, it could be argued that our findings are constrained in their interpretive power.

\section{Value as a Thematic Concept}

The second category contains papers in which value (and value-related concepts) is used in a thematic way. 
Looking at the results of the review, we identify evaluation as the dominating search term within the thematic concept category. What is surprising is that despite the current and upcoming societal debates on ethics, morals, and sustainability, these concepts/areas are not represented in high frequencies in the review. Among these three areas, environmental sustainability is the most commonly used area. The different journals seem to complement each other in the thematic category, where gaps on search terms within one journal are filled by one or more other journals. Overall, this is the value category that is the most widely represented in published research and also visible through the large number of partly inductively emerging search terms. The total within the thematic concept category is dominated by IEEE-TEM and IJPM, which both largely contribute with high frequencies; this strong dominance can however not be explained purely by the largest number of volumes in the review. From a philosophical perspective, the selection of one value concept over the other or a specific definition of a value concept makes a difference. Such choices are influenced by the researchers' situatedness in a certain research community and previous experiences in the project field. Questions such as, 'Is there a common understanding of a value theme?' or 'Is the way of applying value concepts rather fragmented across the project domain?' are thus philosophically relevant issues for the project field to address.

\section{Value Theory}

The third category of studies we have identified covers papers that have used value theory as a basis or as a part of the analysis. This category is thus strongly influential for the study findings because it applies a certain value perspective. It is a way to infuse value theory to the core of a study, which means that value becomes emphasized throughout the study, reaching a philosophical relevance for interpretation. Our review clearly shows that value-related terms are hardly used in any articles across the journals. This observation is underlined further by the fact that three out of the four search terms without any hits were from the value theory category. In this category, we only received very few hits overall and there is no search term that really sticks out. The total in the value theory category is only sourced with papers primarily from IEEE-TEM and one hit from $P M J$ on the subject of instrumental value.

\section{Value Outcome}

The fourth category consists of the papers in which value is treated as an outcome. This group is represented by three search terms that capture articles on a project's value creation and its analysis. Value creation has been the most frequently used term in this value outcome category although, compared with other value categories, it is still rarely used. Although value creation has been a theme in four of five journals, our review indicates that it has received the most attention in IJPM publications as presented in the row on the total of value outcome. IJMPB, although being a young journal, contributes with comparable frequencies compared with the long-established IEEE-TEM, which adds only a few hits in relation to the range of publication years. Emphasizing value outcomes is a direct way to show the relevance and contribution of the project field. Thus, showing the value of project management in a transparent and reflective way also requires a good understanding of the philosophical underpinnings of what we accept as indicators of "favorable," "good," or "valuable" outcomes.

\section{Values in Project Management Methodology}

The fifth and final category is the one in which values are a central part of the project management methodology; examples thereof are the commonly used concepts of net present value, earned value management, and PERT.
At the same time, these were the most frequently used terms within the project management methodology category, with PERT clearly dominating in its frequency. Earned value management and PERT affirm this observation by having hits across all five journals. The search terms with lower hits in this category are often related to the three most common terms. For example, earned value methodology and earned value analysis are closely related to the established notion of earned value management. The inclusion of such related search terms arises from inductively adding search terms, where unless a query has been conducted, it cannot be known how common or uncommon they are in advance. The totals of the category 'project management methodology' (see Table 2) highlight the main contributors of IEEE-TEM and IJPM and also show that in IJPOM, as a young journal, there seems to be an ongoing debate. IJPOM shows similar frequencies compared with the long established PMJ, thus indicating that in value-related terms, IJPOM papers emphasize rather practical methodologies rather than value theories. Furthermore, the selection of the project management methodology has a philosophical dimension to it. Depending on the researcher's standpoint or dominating position of the project community concerning scheduling, controlling, or risk management, a certain methodology is followed in the study. The selection of one framework over the other is in its essence a philosophical choice although it is hardly discussed or reflected upon. The choice of a particular methodology represents one perspective on project management, which emphasizes certain elements and fits to certain project contexts while leaving out the "reality" beyond those assumptions.

\section{Value Categories Over Time}

Having looked at the frequencies of search terms across the different journals (Table 2) and provided shorter reflections on these results, now we take 


\begin{tabular}{|l|l|l|l|l|}
\hline Frequency in & Period 1 & Period 2 & Period 3 & \multicolumn{1}{l|}{ TOTAL } \\
\hline Title/Keywords/Abstract & $\mathbf{1 9 6 3 - 1 9 9 4}$ & $\mathbf{1 9 9 5 - 2 0 0 5}$ & $\mathbf{2 0 0 6 - 2 0 1 5}$ & $\mathbf{1 9 6 3 - 2 0 1 5}$ \\
\hline [...] Value [...] & $13 / 3 / 65$ & $29 / 24 / 120$ & $75 / 91 / 257$ & $\mathbf{1 1 7 / 1 8 / 4 4 2}$ \\
Value in the research process & $0 / 0 / 0$ & $0 / 0 / 0$ & $0 / 0 / 1$ & $\mathbf{0 / 0 / 1}$ \\
Value as a thematic concept & $48 / 11 / 185$ & $48 / 29 / 188$ & $110 / 113 / 355$ & $\mathbf{2 0 6 / 1 5 3 / 7 2 8}$ \\
Value theory & $0 / 0 / 2$ & $0 / 0 / 0$ & $1 / 1 / 2$ & $\mathbf{1 / 1 / 4}$ \\
Value outcome & $2 / 0 / 0$ & $0 / 1 / 1$ & $5 / 6 / 20$ & $\mathbf{7 / 7 / 2 1}$ \\
Value in project management methodology & $13 / 3 / 28$ & $12 / 17 / 28$ & $12 / 22 / 41$ & $\mathbf{3 7 / 4 2 / 9 7}$ \\
\hline Table 3: Treatment of values over time. & & & &
\end{tabular}

a look at the treatment of values over time. Hereby, we group the total frequencies for the different time periods by including the publications from the available journals within the particular time period (see Table 3 ).

The row on value represents a category in itself because it overlaps across the five different categories. Nevertheless, as the key concept it provides us with valuable insights on an aggregated level and shows that there is such a strong increase in the publications using the value term within the third period (2006-2015) that cannot be fully explained with the number of journals available. From this observation, it can be argued that there seems to be an ongoing general trend toward more value-related articles.

There are three value categories that specifically characterize the treatment of values over time. First, concerning the category of value as a thematic concept, there seems to be a continuous trend toward increasingly using such topics in research. Although periods one and two are comparable in absolute numbers, the second period contains much fewer journal volumes, whereas the third period shows a strong increase even when considering the number of journals. Second, value in project management methodology has been rather stable in absolute numbers. Even when considering the availability of journals and papers throughout the three time periods, it seems that the number of articles per year has increased from period one to two and thereafter has stabilized at a certain level, indicating that it is an ongoing common topic within project research. Value outcome is the third category in which we can observe trends over time. Although value outcome is rarely used, there seems to be an emergence in the third period, whereas in earlier periods it was hardly addressed at all.

As observed in Table 3, the use of value (and value concepts) as a part of both the research process and basis on value theory is close to non-existing; during the third time period (20062015), however, there are a few exceptions. This observed plausible lack of treatment needs further exploration before any clear conclusions can be drawn.

\section{Paradigmatic and Historical Influences on Values}

Based on the three initially presented value dimensions (Hartman, 1961, 1962, $1967,2014)$, the next step in our quest to take stock of values is to explore the above identified 'lack of treatment,' and thus if the identified categories in some way (on a more aggregated level) are reflected in the historical development of-or perspectives on-projects and their management.

Even if most historical descriptions of projects take their starting points from the U.S. military industry complex prior to (and around) World War II, some attempts have been made to go even further back in time. Because we are interested in the characteristics of and values embodied in the understanding of projects, we have chosen to follow the proposed categorization by Gauthier and Ika (2012) into four historical perspectives of premodern-, modern-, postmodern-, and hypermodern project management. It should be noted, however, that there have been many other attempts to outline the history and development or parts thereof (see, e.g., Engwall, 1995, 2012; Pinney, 2002; Geraldi \& Lechter, 2012), but none of these provides such an interrelated and focused discussion on ontological and epistemological issues as Gauthier and Ika (2012). To further extend the historical-logical analysis, we have opted to also utilize the revised conceptualization of research paradigms, provided by Lincoln, Lynham, and Guba (2011). Following the extensive critique by Heron and Reason (1997), the notion of axiology and the role of value were recently added to the often-used overview (Lincoln et al., 2011) and consequently overlap with the subject of this article. With our extension, we are thus able to provide a more complete characterization of the modernity perspectives in terms of the philosophies in project management.

\section{Values in the Premodern Perspective of Projects and Their Management}

The first historical phase outlined by Gauthier and Ika (2012, p. 12) is the socalled 'premodern perspective on projects', where the project is seen as, and represented by, "a creation of human beings that serves gods and, as such, deserves the respect of human beings". 
This perspective on projects is furthermore characterized by the management of projects being an activity ". . . that follows the laws of gods," which Gauthier and Ika (2012) explain with a project, at that time, not being designed to serve progress as today, but rather honor certain goods such as, for example, the erections of temples. The project manager figure, from this perspective, is described as a priest.

Given the description by Gauthier and Ika (2012), projects from the 'premodern perspective' clearly represent something intrinsically good because the management of projects was not an issue per se, but rather the focus was on the universal fulfillment of societal needs. With projects being an activity ". . . that follows the laws of gods," both the outcome and the project per se would thus be good "in itself" and "in its own right." From such a perspective, it was thus the sole outcome that was counted. Even if this perspective predates the structured research on projects, one could argue that the role (and view) related to value were intrinsic; still, it is difficult, if not impossible, to draw any conclusion regarding the major paradigmatic influences or ontological orientation of this era.

\section{Values in the Modern Perspective of Projects and Their Management}

The second phase presented by Gauthier and Ika (2012, p. 12) is the so-called 'modern perspective on projects.' From this perspective it is suggested that the project is to be seen as ". . . a temporary endeavor undertaken to create a unique product and service and is designed to serve progress." Project management is furthermore acknowledged as a ". . . technocratic, instrumentalist, and rationalist approach" following the tradition of the scientific management. It is furthermore described that it is central to "capitalism, industrialism, and military growth" and the management aims to provide controllability. From the 'modern perspective on projects' the project manager figure is portrayed as an architect (Gauthier \& Ika, 2012, p. 12).

Following the arguments by Lincoln et al. (2011), the technocratic and rationalist approach put forward by Gauthier and Ika (2012), characterizing the 'modern perspective on projects,' is closely related to a positivist, or postpositivistic, perspective that primarily employs an extrinsic understanding of values. As initially described, following the need of belonging to a certain class or category, extrinsic values are connected to a specific functionality, which is in line with a rationalist approach. In the research process, value influences are mostly denied, but as highlighted by Hiles (2008, p. 55) when values are considered from such a perspective, it is often relying on "ethical codes, ethics committees, and the accepted standards of good practice." The strong reliance on "standards of good practices" is also visible in a lot of the prospering literature from the 1980s and beginning of the 1990s. Project outcomes were, for example, often solely evaluated in a systemic way, meaning a valuation based purely on a few characteristics; either the project met the characteristics set up and was a success, or it didn't meet the characteristics and was a failure. Such instrumental and dichotomous understanding was one of the many critiques that served as the basis for the new type of project research that came out of the Scandinavian countries with a start in the mid-1990s (Packendorff, 1995; Hällgren, Jacobsson, \& Söderholm, 2012). Following Lincoln et al. (2011), the major ontological orientation of this perspective would also be a 'being ontology' that is external from cognition.

\section{Values in the Postmodern Perspective of Projects and Their Management}

The third phase outlined by Gauthier and Ika (2012, p. 12) is the so-called 'postmodern perspective,' in which “. . . the project is a discourse of legitimation, and an arena of social and power plays; it serves the interests of the powerful stakeholders." In this phase, project management is "neither a practice nor a tool but a rallying rhetoric in a context of power play, domination, and control." According to Gauthier and Ika (2012, p. 12) there is thus no good or bad forms of project management, “. . . because uncontrollability, absence of meaning, multiplicity, ambivalence, and fragmentation/pluralism characterize project management." Instead of the project manager figure being a priest or an architect-as represented in the previous two examples-here it is a "rhetor" (Gauthier \& Ika, 2012, p. 12).

In the transition from a modern to a postmodern perspective of projects and their management, Pollack (2007) found that research had incrementally shifted direction from a predominance of hard (operations) issues investigating critical success factors, to softer (behavioral) issues, such as human resource management (Bredin \& Söderlund, 2006), project teams (Chiocchio \& Hobbs, 2014; Shelley \& Maqsood, 2014), and relational coordination (Jacobsson, 2011). Interesting to note in the conceptualization by Gauthier and Ika (2012, p. 12) is that they state that projectsfrom a postmodern perspective-are "neither a practice nor a tool."

Following the arguments by Given (2008, p. 55), researchers with a postmodern perspective on projects-where the major paradigmatic influences would be critical theory and constructivismwould thus ". . . accept the established codes of ethically sound practice but goes farther by striving toward a transparency of values [...] and also applies a "process ethics" to the forms of knowing that the specific context of the inquiry requires." This means that a postmodern perspective on projects adheres to values being of systemic character, which could further be exemplified by the discourses and pluralism from the making projects critical movement, which takes a wider stand and integrates scientific inquiries to being an element in a system. This broader, or more inclusive, perspective on projects also seems to be well covered 
with the thematic concept category (see Tables 2 and 3), and its search terms on ethics, moral, sustainability, reward, and motivation. The major ontological orientation would thus also be a becoming ontology, cognitive, and hermeneutic (cf. Lincoln et al., 2011), in which the understanding of values in the research process is included and formative.

\section{Values in the Hypermodern Perspective of Projects and Their Management}

The fourth and final phase described by Gauthier and Ika (2012) is the socalled 'hypermodern perspective,' in which "the project is a network of actors embedded in a social context and in constant transformation." The project is considered as a work in progress and the "project management is a reflexive practice." From a hypermodern perspective, the project manager figure is no longer a rhetor but instead described as a reflexive agent (Gauthier \& Ika, 2012, p. 12).

Assessing the conceptualization of the hypermodern perspective, it mainly corresponds to values being understood as logical, systemic, and formative in their character. The major paradigmatic influences would thus also be critical theory and participatory approaches, with project management not only being considered a "reflexive practice," but also the project figure as a reflexive agent. With the hypermodern society (and by that, the hypermodern perspective of projects and their management), building on the notion of society as a network of reflexive individuals (Gauthier \& Ika, 2012), an extrinsic understanding of values might come into play, because reflexivity needs consideration in relation to the functionality in a specific system. For the hypermodern perspective to really take off, there would thus be (as we believe) a need to bring in more value theory and develop a better understanding of the role of value in the research process in order to be reflexive within the wider system.

As discussed above and summarized in Table 4, each of the perspectives on projects and their management also encompass some major paradigmatic influences, specific ontological orientations, and thereof axiological configurations (Gauthier \& Ika, 2012; Lincoln et al., 2011). Based on Lincoln et al. (2011) and their comparison of the basic beliefs of different paradigms (i.e., positivism, post-positivism, critical theory, constructivism, and participatory approaches), we have also attempted to assess the interrelated treatment of values, which varies from 'intrinsic' in the premodern perspective; via 'extrinsic, with value influences denied in the research process' in the modern perspective; to being 'systemic, included, and formative' on the postmodern perspective. In terms of the hypermodern perspective, the treatment of values is somewhat in the future, but following Lincoln et al. (2011), it would seem to be central to the quest and formative.

\section{Discussion: The Roles of Values in Project Research}

Bringing together the results from our reading of the axiology and value theory literature, with our review, and the more qualitative historical-logical assessment of research paradigms and value influences, we have-beyond the already presented value categories as shown in Table 3-been able to outline a framework consisting of four different

\begin{tabular}{|c|c|c|c|c|}
\hline & $\begin{array}{l}\text { Premodern } \\
\text { Perspective }\end{array}$ & $\begin{array}{l}\text { Modern } \\
\text { Perspective }\end{array}$ & $\begin{array}{l}\text { Postmodern } \\
\text { Perspective }\end{array}$ & $\begin{array}{l}\text { Hypermodern } \\
\text { Perspective }\end{array}$ \\
\hline $\begin{array}{l}\text { Project metaphor } \\
\text { (Gauthier \& Ika, 2012, p. 12) }\end{array}$ & $\begin{array}{l}\text { "... a creation of human } \\
\text { beings that serves gods } \\
\text { and, as such, deserves the } \\
\text { respect of human beings" }\end{array}$ & $\begin{array}{l}\text { "... a temporary endeavor } \\
\text { undertaken to create a } \\
\text { unique product and service } \\
\text { and is designed to serve } \\
\text { progress" }\end{array}$ & $\begin{array}{l}\text { "... a discourse of } \\
\text { legitimation, and an } \\
\text { arena of social and } \\
\text { power plays; it serves } \\
\text { the interests of the } \\
\text { powerful stakeholders" }\end{array}$ & $\begin{array}{l}\text { "... a network of actors } \\
\text { embedded in a social } \\
\text { context and in constant } \\
\text { transformation. The project is } \\
\text { a work in progress" }\end{array}$ \\
\hline $\begin{array}{l}\text { Project management figure } \\
\text { (Gauthier \& Ika, 2012, p. 12) }\end{array}$ & Priest & Architect & Rhetor & $\begin{array}{l}\text { Practitioner as a reflexive } \\
\text { agent }\end{array}$ \\
\hline Major paradigmatic influences & $\mathrm{N} / \mathrm{A}$ & $\begin{array}{l}\text { Positivism and post- } \\
\text { positivism }\end{array}$ & $\begin{array}{l}\text { Critical theory and } \\
\text { constructivism }\end{array}$ & $\begin{array}{l}\text { Critical theory and } \\
\text { Participatory approaches }\end{array}$ \\
\hline Ontological orientation & $\mathrm{N} / \mathrm{A}$ & $\begin{array}{l}\text { Being ontology, external } \\
\text { from cognition }\end{array}$ & $\begin{array}{l}\text { Becoming ontology, } \\
\text { cognitive and } \\
\text { hermeneutic }\end{array}$ & $\begin{array}{l}\text { A practice or becoming } \\
\text { ontology, cognitive }\end{array}$ \\
\hline $\begin{array}{l}\text { Axiology (nature, and role of } \\
\text { value) }\end{array}$ & Intrinsic & $\begin{array}{l}\text { Extrinsic, and value } \\
\text { influences in process } \\
\text { denied }\end{array}$ & $\begin{array}{l}\text { Systemic, included and } \\
\text { formative }\end{array}$ & $\begin{array}{l}\text { Both systemic and extrinsic, } \\
\text { central to the quest and } \\
\text { formative }\end{array}$ \\
\hline
\end{tabular}


ways in which 'values' and (project) research intersect:

1. First, we can observe an intersection where values are present through the focus of the scientific inquiry itself, both in terms of values (a valuerelated terminology) being a 'thematic concept,' and a part of 'project management methodology.'

This type of influence is clearly identifiable in the review (see Tables 2 and 3) and probably also the most easily recognized, least questioned, type of value intersection within project research. Looking closely at the review, it is also clear that this type of value intersection is well represented both in terms of absolute numbers and frequency over time. It also, to a large extent, represents an externalized treatment of values present in all the historical perspectives (Gauthier \& Ika, 2012) where, for example, influences from value assessments in economic theory are observable. It should be noted that the use of values in this first type of intersection, however, does not say anything about the research process or the mindset of the researcher, apart from an (probable) interest in the assessed terminology such as 'earned value management,' 'value outcome,' or lately 'ethics.'

Moving beyond this type of externalized treatment, one could argue that researchers should not focus on the type of 'subjective questions' that a more engaged treatment would imply. Following the classical ideals central to the 'modern perspective of projects and their management' (Gauthier \& Ika, 2012), researchers are taught that science should be objective and valuefree, and researchers should act in a rational and unbiased way (Lincoln et al., 2011). But the true existence of totally value-free, or value neutral science is, according to Hiles (2008, p. 53) "little better than a myth." The reason, he argues, is that research is always based on a wide variety of choices and assumptions, which inevitably are value based. We can exemplify this by looking at the starting point of this article. Our basic assumption has been that axiology and value theory are important for project research (otherwise we would not have explored this issue); we have chosen to limit the review to five peer-review journals based on our understanding of publication history in relation to the audience (the latter of which we have no control over); we assume that the future readers of this article are somewhat familiar with the premises of project research (but we don't know this for certain); and we have chosen to follow the arguments by Mingers (2003) insomuch as the writing of this article has been undertaken from a pluralistic perspective-consequently adhering to the assumption (and belief) that pluralism extends not only to ontology, epistemology, methodology, but also to axiology. A different set of researchers would probably have valued other aspects and made different choices; hence, we thus adhere to the argument that values are a central part of the scientific inquiry per se.

2. The second type of intersection is therefore represented by the type of 'personal' values that-consciously or unconsciously-guide the individual researcher in the research process.

This type of intersection is thus broader than the first type and manifests itself in, for example: the choice of research problem, choice of theoretical framework, choice of data-gathering, and choice of data-analytic method (Hartman 1961, 1962, 1967; Lincoln et al., 2011, p. 116). This is also reflected in what is seen as important, who is to 'benefit' from a study, and what type of value is added to the existing knowledge base (see, e.g., Mingers, 2003, for further discussion).

Looking at the review, it can be concluded, however, that an explicit treatment of this type of value (i.e., 'values in the research process' and 'value theory') is almost non-existent. Despite not being recognized (or at least not explicitly discussed or mentioned) in the abstracts, the fact that values feed into the inquiry process is consequently neither a new observation, nor limited to project research. Paraphrasing Hiles (2008, p. 53), as scientific inquiry leads to knowledge; knowledge, in turn, leads to the imposition of some type of ordering in the world. This 'ordering' consequently involves issues of value. ${ }^{2}$ Statements along the line of 'science is objective, values are not' may offer comfort to some scientists who want to see themselves detached from questions such as the role of values in research ( $c f$. Table 4, "nature and role of value in positivism and post-positivism"). However, it can be concluded that such statements do not reflect the existing pluralism in contemporary project research and is neither central to the postmodernnor the hypermodern perspective of project management (Gauthier \& Ika, 2012). Important to note in this regard is also that the selected method implicitly brings out certain aspects of the world, whereas other interpretations or characteristics are simultaneously put into the shadows. As stressed by Mingers (2003, p. 562), this does not necessarily imply that the existence of other interpretations, characteristics, or dimensions are denied, but rather "the method simply makes no reference to them." With the observed lack of explicit treatment in the reviewed literature, one might rhetorically ask: What else is still hiding in the shadows?

3. Third, we can observe an intersection related to the types of values (and value propositions) that emerge as a result of the scientific inquiry andoften in a dutiful way-are redistributed into society through, for example, managerial and policy implications.

\footnotetext{
${ }^{2}$ Verbatim: “Moreover, inquiry leads to knowledge, and knowledge leads to the imposition of some type of order or structure on the world-and this always involves issues of value" (Hiles, 2008, p. 53).
} 
This third type of intersection is not easily traced in its conceptual use, and thus rarely acknowledged as values per se, but rather seems to be central to the raison d'être of the project field. However, it reflects in some sense, the paradigmatic influences of the modern perspective on projects, where the project is considered as “. . . a temporary endeavor undertaken to create a unique product and service and is designed to serve progress" (Gauthier \& Ika, 2012, p. 12). Thus, with a focus on the creation of "a unique product and service" it clearly entails an emphasis on material, physical, and economic value (Rescher, 1969), rather than, for example, social or environmental values (Silvius \& Schipper, 2014). The value of the research from 'a modern perspective on projects' is given by the project as such - the creation of a unique product or service.

Connected to this observation and taking into consideration the historical roots of project management-and thereby the closeness to practitionersthere often seems to be a consequentialist rationale (or logic) in project research. This logic means that research results are transformed in a 'value independent' way into managerial implications, in which 'good' or 'bad' implicitly have a bearing on what ought to be done (or not done) in practice. In a sense, this might be a reflection of the strong positivism and post-positivism influences in the modern perspective (Gauthier \& Ika, 2012), with a priori given parameters of what a good project is. Here, the role of time becomes an important parameter, where short-, medium-, and long-term orientations (of project objectives and outcomes) emerge as important queries in relation to what is to be valued as an outcome. Potentially, this is reflected in the growth of for example environmental sustainability, which often brings about such a perspective (Silvius \& Schipper, 2014). Consequently, this third type of intersection is also related to the former second type, because the question of what the outcome is, is related to who is to 'benefit' from it-both important philosophical questions that researchers need to seriously consider in their research.

4. Fourth and final, drawing on the paradigmatic influences (Lincoln et al., 2011; Heron \& Reason, 2007) and the historical-logical development (Gauthier \& Ika, 2012), we can further conclude that values intersect with projects in the form of 'epistemic values.'

This type of value intersection is inherent in the research paradigms that different perspectives and traditions convey and researchers adhere to (see Table 4). Epistemic values are thus related to the two previously described intersections, but exist on a more aggregated level with reference to researchers' embeddedness in a certain research community. Looking at the review, it can be concluded that an axiological discussion reflecting this situatedness is non-existent (at least under the assessed terminology). The paradigmatic influences on epistemic values can however be broadly captured with the question of: What type of research is to be, or has been valued? This is a question where the answer is of a systemic character rather than an extrinsic (or intrinsic) one and is also dependent on the power and competing worldviews or 'paradigms.' From an historical point of view (Packendorff, 1995; Söderlund, 2004; Pollack, 2007; Gauthier \& Ika, 2012), we can observe a collision between (at least) two value systems-an economics and engineering (as the application of systemic and extrinsic value to things) and an organizational behavior/sociology (as the application of extrinsic value to humans and society). Reflecting on the hypermodern perspective of projects and their management, yet another collision might be heading toward the project research community in the near future. With projects (from a hypermodern perspective) being considered based on their systemic character, the phenomena would thus be connected to the functionality it is supposed to have in a specific context (Hartman, 2014). Consequently, projects need to be considered in their extended context, also taking long-term goals and consequences into consideration-potentially also questioning the raison d'être.

It should be noted that all research involves a great variety of epistemic values indirectly influencing the research practice. As stressed by Allchin (1998), this isn't all bad because it also helps in governing the productions of knowledge through, for example, regulating research quality.

\section{Conclusions}

The rationale for this article was based on the need to take stock of values and axiology in project research. Following-among others-the contemporary societal development in which policymakers and organizations alike are increasingly concerned with values for educating an ethical and responsible workforce, the purpose was to explore the role and potential benefits of axiology and value theory in project research. This quest was approached in three interrelated steps. First, we outlined the essentials of axiology and value theory. Second, we undertook a review with a focus on how values-in a broad sense-have been used in project research. Third, we juxtaposed the premodern-, modern-, postmodern-, and hypermodern project management perspectives-as representations of the field development along with the various value approaches. Through these steps we have attempted to both outline the current use of values and value concepts in project research, and discuss the more implicit, less tangible and holistic role of values.

From the study, we can first and foremost conclude that value(s), and value-related concepts are clearly present in the form of thematic concepts and project management methodology; however, axiology, value theory, and the 
role values play in research, are rarely discussed even if scholars have recognized their importance and potential to enrich research. Furthermore, projects are not (from either a modern-, postmodern-, or hypermodern perspective) viewed as having intrinsic value even if project researchers sometimes tend to treat projects as a phenomenon that is 'good' in its own right.

Based on these initial observations, and following other researchers' observations of the importance to also acknowledge the less tangible role of values (see, e.g., Heron \& Reason, 2007; Lincoln et al., 2011; Gauthier \& Ika, 2012; Hartman, 2014), we outlined a framework of four different ways in which values intersect with project research: (1) an intersection where values are present through the focus of the scientific inquiry itself; (2) an intersection represented by the type of 'personal' values that guide the individual researcher in the research process; (3) an intersection related to the type of value propositions that emerges also as a result of the scientific inquiry; and (4) an intersection in the form of 'epistemic values' inherited in different research paradigms. When reflecting on these four intersections, it is obvious that they all (in different ways) have a clear impact on the research process and outcome, and thus calls for philosophical considerations. From the perspective of the individual researcher, the intersections thus imply consideration of the following questions:

- In what context is the research situated (paradigmatic influences)?

- What are the philosophical values chosen and why (guiding the inquiry)?

- Why is a specific inquiry chosen (focus of research)? and,

- Which claims are made (and suggestions to practitioners)?

At the core of these intersections consequently lies the importance of value reflexivity and value consideration.
Thus, it is clear that values-despite what is sometimes claimed-are constantly present through researchers' underlying assumptions and choices of topics. Here it is important to point out that our main argument with regard to these intersections is not that there is a problem with researchers making choices and having assumptions, per se, but rather that a problem arises when researchers are ignorant to the consequences thereof. Or, in an unreflective way take their assumptions-and thereby their values-for granted. Following Lincoln et al. (2011), we therefore propose that a sufficient understanding and reflection on axiology and values is equally as important for the outcome as for the understanding and reflection on methodological-, ontological- and epistemological issues-upon which importance most researchers agree. If researchers would be more explicit in describing their philosophical/axiological standpoints, it would also allow the project research community to take part in philosophical debates that may challenge assumptions that remain unquestioned and are taken for granted. We conclude that being more explicit about values is important, as the field is both based on and takes its pride in the diverse sources of contribution. A central argument to bring forward here is the closeness to practitioners and the often-present consequentialist rationale among researchers, in which claims of 'good' or 'bad' implicitly have a bearing on what ought to be done (or not done) in practice. The question: "Good for what?" consequently becomes relevant. Or as Heron and Reason (1997, p. 277) write: “. . . the axiological question asks what is intrinsically valuable in human life, in particular what sort of knowledge, if any, is intrinsically valuable"-following this, we suggest that researchers interested in projects bring this question to the top of their agendas.

Moving beyond the individual researcher, it is thus possible to argue that axiology per se, is the lens needed to understand projects on an in-depth level. Following the call for this Special Issue, where it was stated that: "we must first care for the perspective/philosophy from which projects are seen and analyzed in academia," it is clear that axiology is one important dimension to it. The general understanding of axiology and value theory also provides the basis for the scientific community to be able to address and discuss core philosophical questions, such as: What should be or ought to be the purpose of managing projects? What are the moral-, social-, economical rights and obligations of the project manager, project sponsors, or other stakeholders? Without a proper understanding of values and why something is valued, these questions are impossible to address. Consequently, there is an abundance of unanswered questions-both on an individual and collective level-to which axiology and value theory can be used when trying to answer. In order to propel the field of project research forward, we therefore suggest that axiology should be established as a central theme in both teaching and research. This would not only enable the evolution of project management research and practice, but also provide an opportunity to strengthen the legitimacy of the research field as such.

To summarize, our contribution with this article is threefold. First, we provided a basic understanding of how values are used within the project research field and the roles they play in research's philosophical underpinning. Second, we made an initial attempt to establish a framework in relations to which the value of projects and project research can be discussed. Third, we provided suggestions for how both individual researchers and the research community can progress via (among others) enabling reflexivity and philosophical reflections in a more fundamental way. Using the words of Bredillet, Tywoniak and Dwivedula (2015, p. 10): "The knower and the known always relate to each other." 


\section{Limitations and Future Directions}

Similar to most articles, this one also has limitations that favourably can be recognized and addressed in future studies. First, with our article building on a simple but comprehensive review of articles published in five journals between 1963 and 2015, it is constrained by the fact that we have only assessed the key sections of the articles (i.e., titles, keywords, and abstracts) for queries with value-related terms. Although this approach is appropriate in order to cover articles with value-related terms as a central theme, it can't capture the implicit treatment and meaning of values and its related concepts. Further research could preferably be designed as an in-depth content analysis of one of the major project management journals to differentiate between the implicit and explicit use of values in contemporary project research; or, address which value concepts are favored and/ or neglected in project management methodologies, and explain why that is. Second, when conducting our review, we also used a list of search terms we identified as being at the core of capturing the axiology and value-relevant concepts in project research. Rather than using an excessive and 'complete' list containing all possible search terms and overlapping combinations thereof, our intention was to capture the field's pluralism by including all the publications from the five main project management journals and use its results for our analysis and conceptual reflection. Further research could thus also conduct, for example, an in-depth analysis of the specific search terms in a specific journal.

\section{References}

Abidin, N. Z., \& Pasquire, C. L. (2007). Revolutionize value management: A mode towards sustainability. International Journal of Project Management, 25(3), 275-282.

Allchin, D. (1998). Values in science and in science education. In B. J. Fraser \& K.
G. Tobin (Eds.), International Handbook of Science Education, Dordrecht, The Netherlands: Kluwer Academic Publishers, 1083-1092.

Alvesson, M., \& Sköldberg, K. (2009). Reflexive methodology: New vistas for qualitative research. London, England: Sage.

Biedenbach, T., \& Müller, R. (2011).

Paradigms in project management research: Examples from 15 years of IRNOP conferences. International Journal of Managing Projects in Business, 4(1), 82-104.

Bredillet, C. N. (2010). Blowing hot and cold on project management. Project Management Journal, 41(3), 4-20.

Bredillet, C., Tywoniak, S., \& Dwivedula, R. (2015). What is a good project manager? An Aristotelian perspective. International Journal of Project Management, 33(2), 254-266.

Bredillet, C., Tywoniak, S., \& Dwivedula, R. (2015). Reconnecting theory and practice in a pluralistic organizing context: Issues and Aristotelian considerations. Project Management Journal, 46(2), 6-20.

Bredin, K., \& Söderlund, J. (2006). HRM and project intensification in R\&D based companies: A study of Volvo Car Corporation and AstraZeneca. $R \& D$ Management, 36(5), 467-485.

Cameron, R., Sankaran, S., \& Scales, J. (2015). Mixed methods use in project management research. Project Management Journal, 46(2), 90-104.

Chiocchio, F., \& Hobbs, B. (2014). The difficult but necessary task of developing a specific project team research agenda. Project Management Journal, 45(6), 7-16.

Cicmil, S., Williams, T., Thomas, J., \& Hodgson, D. (2006). Rethinking project management: Researching the actuality of projects. International Journal of Project Management, 24(8), 675-686.

Corvellec, H., \& Macheridis, N. (2010). The moral responsibility of project selectors. International Journal of Project Management, 28(3), 212-219.
Edum-Fotwe, F. T., \& Price, A. D. (2009). A social ontology for appraising sustainability of construction projects and developments. International Journal of Project Management, 27(4), 313-322.

Edwards, R. B. (2014). Systemic value and valuation. In: Edwards, R. B. and Davis, J. W. (Eds.) Forms of value and valuation: Theory and application. Eugene, OR: Wipf and Stock Publishers, 37-58.

Engwall, M. (1995). Jakten på det effektiva projektet (The dream of the effective project management), $\mathrm{PhD}$ thesis, the Royal Institute of Technology: Stockholm, Sweden.

Engwall, M. (2012). PERT, Polaris, and the realities of project execution. International Journal of Managing Projects in Business, 5(4), 595-616.

Gauthier, J. B., \& Ika, L. A. (2012). Foundations of project management research: An explicit and six-facet ontological framework. Project Management Journal, 43(5), 5-23.

Geraldi, J., \& Lechter, T. (2012). Gantt charts revisited: A critical analysis of its roots and implications to the management of projects today. International Journal of Managing Projects in Business, 5(4), 578-594.

Given, L. M. (Ed.). (2008). The Sage encyclopedia of qualitative research methods. Thousand Oaks, CA: Sage Publications.

Gustavsson, T. K., \& Hallin, A. (2014). Rethinking dichotomization: A critical perspective on the use of "hard" and "soft" in project management research. International Journal of Project Management, 32(4), 568-577.

Hart, S. L. (1971). Axiology: Theory of values. Philosophy and Phenomenological Research, 32(1), 29-41.

Hartman, R. S. (1961). The logic of value. The Review of Metaphysics, 14(3), 389-432.

Hartman, R. S. (1962). Axiology as a science. Philosophy of Science, 29(4), 412-433.

Hartman, R. S. (1967). The structure of value: Foundations of scientific axiology. Carbondale, IL: Southern Illinois Press. 
Hartman, R. S. (2014). The nature of valuation. In: Edwards, R. B. and Davis, J. W. (Eds.) Forms of value and valuation: Theory and application. Eugene, OR: Wipf and Stock Publishers, 9-35.

Helgadóttir, H. (2008). The ethical dimension of project management. International Journal of Project Management, 26(7), 743-748.

Heron, J., \& Reason, P. (1997). A participatory inquiry paradigm. Qualitative Inquiry, 3(3), 274-294.

Hiles, D. R. (2008). Axiology. In L. M. Given, (Ed.). (2008). The Sage encyclopedia of qualitative research methods. Thousand Oaks, CA: Sage Publications.

Hodgson, D., \& Cicmil, S. (Eds.). (2006). Making projects critical. New York, NY: Palgrave Macmillan.

Hällgren, M., Jacobsson, M., \& Söderholm, A. (2012). Embracing the drifting environment: The legacy and impact of a Scandinavian project literature classic. International Journal of Managing Projects in Business, 5(4), 695-713.

Jacobsson, M. (2011). On the importance of liaisons for coordination of projects. International Journal of Managing Projects in Business, 4(1), 64-81.

Jacobsson, M., Lundin, R. A., \& Söderholm, A. (2015). The Scandinavian turn of project research: Reflections on history and future directions, The 23nd Nordic Academy of Management (NFF), Copenhagen, Denmark, August 12-14, 2015.

Jacobsson, M., Lundin, R. A., \& Söderholm, A. (2016). Towards a multi-perspective research program on projects and temporary organizations: Analyzing the Scandinavian turn and the Rethinking effort, International Journal of Managing Projects in Business, 9(4).

Jacobsson, M., \& Söderholm, A. (2011). Breaking out of the straitjacket of project research: In search of contribution. International Journal of Managing Projects in Business, 4(3), 378-388.

Lincoln, Y. S., Lynham, S. A., \& Guba, E. G. (2011). Paradigmatic controversies, contradictions, and emerging confluences, revisited. In N. Denzin and Y. S. Lincoln (2011). The Sage handbook of qualitative research. Thousand Oaks, CA: Sage Publications.

Lundin, R. A., \& Söderholm, A. (1995). A theory of the temporary organization. Scandinavian Journal of Management, 11(4), 437-455.

Mingers, J. (2003). A classification of the philosophical assumptions of management science methods. Journal of the Operational Research Society, 54(6), 559-570.

Morris, P. W. (2010). Research and the future of project management. International Journal of Managing Projects in Business, 3(1), 139-146.

Mueller, R. W. (1969). The axiology of Robert S. Hartman: A critical study. The Journal of Value Inquiry, 3(1), 19-29.

O'Neill, J. (1992). The varieties of intrinsic value. The Monist, 75(2), 119-137.

Olson, J. (2005). Axiological investigations. PhD thesis. Department of Philosophy, Uppsala University, Uppsala, Sweden.

Packendorff, J. (1995). Inquiring into the temporary organization: New directions for project management research. Scandinavian Journal of Management, 11(4), 319-333.

Pollack, J. (2007). The changing paradigms of project management. International Journal of Project Management, 25(3), 266-274.

Pojman, L., \& Fieser, J. (2011). Ethics: Discovering right and wrong. Boston, MA: Cengage Learning.

Pinney, B. W. (2002). Projects, management, and protean times: Engineering enterprise in the United States,

1870-1960. Enterprise \& Society, 3(4), 620-626.

Rescher, N. (1969). Introduction to value theory. Upper Saddle River, NJ: PrenticeHall.

Saunders, M. N. K., Lewis, P., \& Thornhill, A. (2016). Research methods for business students, (7th edition) Harlow, UK: Pearson.
Shelley, A. W. \& Maqsood, T. (2014). Metaphor as a means to constructively influence behavioural interactions in project teams. International Journal of Managing Projects in Business, 7(4), 752-766.

Silvius, A. J., \& Schipper, R. P., (2014). Sustainability in project management: A literature review and impact analysis. Social Business, 4(1), 63-96.

Smyth, H. J., \& Morris, P. W. (2007). An epistemological evaluation of research into projects and their management: Methodological issues. International Journal of Project Management, 25(4), 423-436.

Söderlund, J. (2004). On the broadening scope of the research on projects: A review and a model for analysis. International Journal of Project Management, 22(8), 655-667.

Söderlund, J. (2011). Pluralism in project management: Navigating the crossroads of specialization and fragmentation. International Journal of Management Reviews, 13(2), 153-176.

Tranfield, D. R., Denyer, D., \& Smart, P. (2003). Towards a methodology for developing evidence-informed management knowledge by means of systematic review. British Journal of Management, 14(3), 207-222.

Turner, J. R., Pinto, J. K., \& Bredillet, C. N. (2011). The evolution of project management research. In P. W. Morris, J. K. Pinto, \& J. Söderlund (Eds.) (2011). The Oxford handbook of project management. Oxford, United Kingdom: Oxford University Press.

Zimmerman, M. J. (2001). The nature of intrinsic value. Oxford, United Kingdom: Rowman \& Littlefield Publishers.

Thomas Biedenbach, PhD, is an Assistant Professor at Umeå School of Business and Economics, Umeå University, Sweden. His research interests focus on projects and temporary forms of organizing, capability-based organization studies, and research methodology. He has published his work in journals, including the Project Management Journal ${ }^{\circledR}$, the International Journal of Project Management, and the International Journal of 
Managing Projects in Business. Recently, he contributed with a chapter on the paradigm as a steering mechanism for new research endeavors to the edited book, Designs, Methods and Practices for Research of Project Management published by Gower. He can be contacted at thomas.biedenbach@ usbe.umu.se
Mattias Jacobsson, $\mathbf{P h D}$, is an Associate Professor at Umeå School of Business and Economics, Umeå University, Sweden. His main research interest is in projects, practice, and temporary organizations and, on dual occasions, he was a prizewinner at the Emerald Literati Network
Awards for Excellence. His work has been published in journals, including Management Decision, Project Management Journa ${ }^{\circledR}$, Services Marketing Quarterly, the International Journal of Managing Projects in Business, and Construction Management and Economics. He can be contacted at mattias .jacobsson@usbe.umu.se 
This material has been reproduced with the permission of the copyright owner. Unauthorized reproduction of this material is strictly prohibited. For permission to reproduce this material, please contact PMI. 